OPEN ACCESS

Edited by:

Jayanta Kumar Patra

Dongguk University, South Korea

Reviewed by:

Sean Doyle,

Maynooth University, Ireland Vani Mishra,

Nanotechnology Application Centre,

India

*Correspondence:

Xiaomei Bie

bxm43@njau.edu.cn

Specialty section:

This article was submitted to

Food Microbiology,

a section of the journal

Frontiers in Microbiology

Received: 06 September 2016

Accepted: 26 October 2016

Published: 17 November 2016

Citation:

Liu H, Gao L, Han J, Ma Z, Lu Z,

Dai C, Zhang C and Bie X (2016) Biocombinatorial Synthesis of Novel

Lipopeptides by COM

Domain-Mediated Reprogramming of the Plipastatin NRPS Complex.

Front. Microbiol. 7:1801.

doi: 10.3389/fmicb.2016.01801

\section{Biocombinatorial Synthesis of Novel Lipopeptides by COM Domain-Mediated Reprogramming of the Plipastatin NRPS Complex}

\author{
Hongxia Liu ${ }^{1}$, Ling Gao ${ }^{1}$, Jinzhi Han ${ }^{1}$, Zhi Ma ${ }^{1}$, Zhaoxin Lu ${ }^{1}$, Chen Dai ${ }^{2}$, Chong Zhang ${ }^{1}$ \\ and Xiaomei Bie ${ }^{1 *}$ \\ ${ }^{1}$ College of Food Science and Technology, Nanjing Agricultural University, Nanjing, China, ${ }^{2}$ College of Life Sciences, Nanjing \\ Agricultural University, Nanjing, China
}

Both donors and acceptors of communication-mediating (COM) domains are essential for coordinating intermolecular communication within nonribosomal peptides synthetases (NRPSs) complexes. Different sets of COM domains provide selectivity, allowing NRPSs to utilize different natural biosynthetic templates. In this study, novel lipopeptides were synthesized by reprogramming the plipastatin biosynthetic machinery. A Thr-to-Asp point mutation was sufficient to shift the selectivity of the donor COM domain of ppsB toward that of ppsD. Deletion and/or interchangeability established donor and acceptor function. Variations in acceptor COM domain did not result in novel product formation in the presence of its partner donor, whereas plipastatin formation was completely abrogated by altering donor modules. Five novel lipopeptides (cyclic pentapeptide, linear hexapeptide, nonapeptide, heptapeptide, and cyclic octapeptide) were identified and verified by high-resolution LC-ESI-MS/MS. In addition, we demonstrated the potential to generate novel strains with the antimicrobial activity by selecting compatible COM domains, and the novel lipopeptides exhibited antimicrobial activity against five of the fungal species at a contention of 31.25-125 $\mu \mathrm{g} / \mathrm{ml}$.

Keywords: plipastatin, biosynthetic complex, COM domain, lipopeptide, NRPS

\section{INTRODUCTION}

Bacillus subtilis is a Gram-positive bacterium that produces broad spectrum amphiphilic lipopeptides with excellent biosurfactant properties and antifungal, antibacterial and antiviral activities (Marahiel et al., 1997; Schwarzer et al., 2003; Batool et al., 2011). Iturins (Hiradate et al., 2002; Yu et al., 2002; Jin et al., 2014), fengycins (Vanittanakom et al., 1986; Guo et al., 2014) and surfactins (Bonmatin et al., 2003; Liu et al., 2015) are the three most well-known families of lipopeptides, which produced by Bacilli. And all of them are synthesized by nonribosomal peptide synthetases via a thioesterase chain release mechanism (Tosato et al., 1997; Finking and Marahiel, 2004; Calcott and Ackerley, 2014). These lipopeptides contain a variable cyclic amino acid portion attached to a variable $\beta$-amino or $\beta$-hydroxy fatty acid (de Faria et al., 2011). The fengycin is actually identical compounds to plipastatin that display slightly structural variations at different salty conditions (Honma et al., 2012). Therefore, the term plipastatin is used throughout this study. 
Plipastatin is composed of $10 \alpha$-amino acids linked to one unique $\beta$-hydroxy fatty acid chain, and two variants (plipastatin A and B) with Val or Ala at position 6 have been reported (Vater et al., 2002; Sun et al., 2006). Plipastatin synthetase contains five distinct NRPSs subunits which assemble to form a co-linear chain in the order of ppsA-ppsB-ppsC-ppsD-ppsE (Figure 1A) that incorporates two (ppsA, B and C), three (ppsD), and one (ppsE) amino acid residues (Figure 1B) into the growing peptide, respectively (Marahiel et al., 1997).

Based on the molecular mechanisms employed by NRPSs, NRPS assembly lines have an enormous potential for biocombinatorial synthesis. Biosynthesis of a defined, full-length product relies on the selectivity of individual modules and their coordinated interplay with donor and acceptor communicationmediating (COM) domains (Chiocchini et al., 2006). In most bacterial NRPS systems, a donor COM domain $\left(\mathrm{COM}_{\mathrm{X}}^{\mathrm{D}}\right)$ situated at the $\mathrm{C}$ terminus of an aminoacyl- or peptidyl-donating NRPS (X) and an acceptor $\mathrm{COM}$ domain $\left(\mathrm{COM}^{\mathrm{A}}\right)$ located at the $\mathrm{N}$ terminus of the accepting partner enzyme (Y) form a matching (compatible) set that forms productive interactions between adjacent modules (i.e., ppsA ppsB1 and ppsB2 ppsC1) (Hahn and Stachelhaus, 2006). Biochemical investigations on the selectivity of NRPSs have helped define sets of compatible inter-module linkers. In principle and in practice, enzymes of a NRPS complex can form other biosynthetic templates, making possible the synthesis of a vast array of novel peptide products via a process that is tantamount to combinatorial synthesis (Sieber and Marahiel, 2005; Fischbach and Walsh, 2006). The COM domain swapping experiments verified the decisive role of COM domains for the control of protein-protein interactions between surfactin NRPS (Chiocchini et al., 2006). The research had demonstrated that point mutation of one of these key residues within the COM domain of TycC1 was sufficient to shift its selectivity from the cognate donor COM of TycB3 toward the noncognate donor COM domain of TycB1 in tyrocidine NRPSs (Hahn and Stachelhaus, 2006). The fragments of COM domains were sequenced in previous study (Hahn and Stachelhaus, 2006), but the interaction between enzymes of a nonribosomal peptide has hardly been studied, which relies on the interplay of COM domains. Therefore, we attempted to

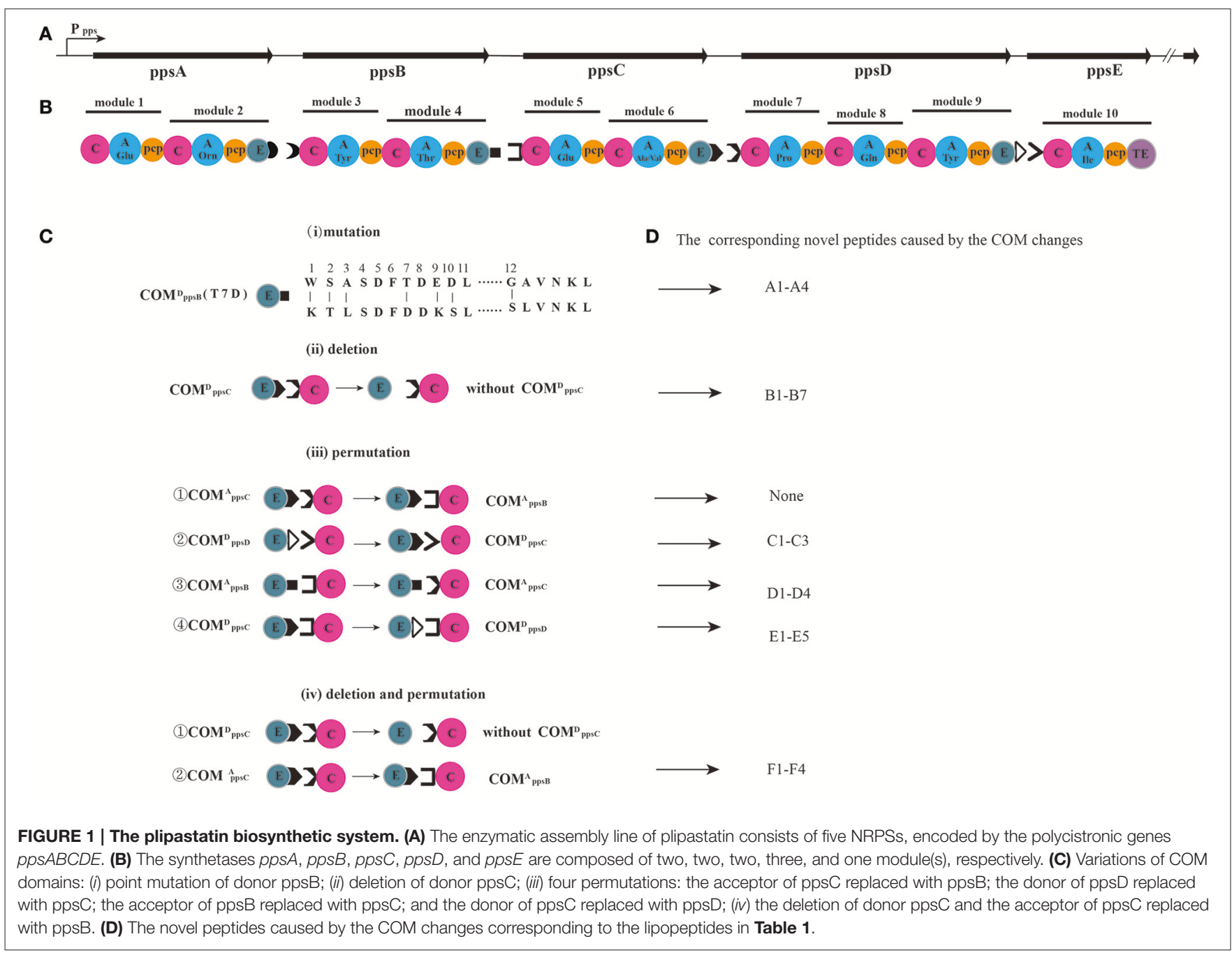


investigate the biocombinatorial synthesis of novel lipopeptides by COM domain-mediated reprogramming of the plipastatin NRPS complex.

The goal of this study was to investigate the influence on protein-protein communication based on the converting donor and acceptor of COM domains sequences, which maintain or prevent the selective interaction between partner NRPSs, furthermore the influence on the novel lipopeptides formation. In this work we began with the B. subtilis PB2-L strain from our previous work, which produces plipastatin (Figure S5) following integration of a gene expression frame composed of a constitutive promoter $\mathrm{P} 43$, functional gene $s f p$, and regulatory gene $\operatorname{degQ}$ into the chromosomal amyE locus of PB2. We studied the importance of COM domains in mediating the specific channeling of reaction intermediates between partner enzymes. First, the effect of site directed mutagenesis of module ppsB on protein-protein communication with the partner elongation module ppsC was explored. Subsequently, the importance and generality of COM domains was further substantiated by COM domain deletion and permutation experiments. This research may provide the theoretical basement for the biocombinatorial synthesis of NRPS complex and the exploitation of novel lipopeptides.

\section{MATERIALS AND METHODS \\ Strains, Media, and General Methods}

Bacterial strains and plasmids used in this work are listed in Table S1. Escherichia coli and Bacillus subtilis were grown in LB medium supplemented with $100 \mathrm{mg} / \mathrm{ml}$ ampicillin, $20 \mathrm{mg} / \mathrm{ml}$ kanamycin, or $5 \mathrm{mg} / \mathrm{ml}$ erythromycin (final concentrations) where applicable. All enzymes were commercial preparations and were used as specified by the suppliers (Vazyme Biotech Co.,Ltd, Nanjing, China and Takara Shuzo Co., Ltd, Dalian, China). E. coli transformation was performed as described previously (Sambrook et al., 1989). The plipastatin biosynthetic complex was reprogrammed using a homologous recombination approach (Figure S1) with upstream (A1) and downstream (A2) primers to construct plasmid pks2A1A2. Similarly, upstream B1 (targeting the tgf gene fragments) and downstream B2 were used to generate plasmid pks2B1B2. The constructs was verified by PCR analysis and used for deletion and substitutions, respectively. After transformation of the plasmids into the host, plasmids were inserted into the chromosome by homologous recombination between the target gene and homologous sequences, or between the homologous sequences alone via the well-established twostep exchange method (Chiocchini et al., 2006). Integration into the chromosome by a single crossover event was selected during growth at the nonpermissive temperature $\left(37^{\circ} \mathrm{C}\right)$ while maintaining selective pressure. Subsequent growth of the cointegrates at the permissive temperature $\left(30^{\circ} \mathrm{C}\right)$ leads to a second recombination event, resulting in their resolution (Arnaud et al., 2004). The novel B.subtilis strains were verified by PCR analysis and the sequences were sequenced by Genscript biotechnology co., LTD (Nanjing, China) (data not shown).

\section{Cloning}

Bacillus subtilis DNA was isolated from enrichment cultures using a bacterial genomic DNA extraction kit (Omega, USA) according to the manufacturer's instructions. Each $50 \mu \mathrm{l}$ reaction contained $35 \mu \mathrm{l}$ of $\mathrm{ddH}_{2} \mathrm{O}, 5 \mu \mathrm{l}$ of $2 \times$ PCR buffer, $4 \mu \mathrm{l}$ of dNTP, $2 \mu \mathrm{l}$ of F-primer, $2 \mu \mathrm{l}$ of R-primer, $1 \mu \mathrm{l}$ of Phanta SuperFidelity DNA Polymerase and $1 \mu$ l of template DNA. The PCR program consisted of an initial denaturation at $94^{\circ} \mathrm{C}$ for $3 \mathrm{~min}$, followed by 30 amplification cycles of $94^{\circ} \mathrm{C}$ for $30 \mathrm{~s}, 60^{\circ} \mathrm{C}$ for $30 \mathrm{~s}$, and $72^{\circ} \mathrm{C}$ for $30 \mathrm{~s}$, then $72^{\circ} \mathrm{C}$ for $10 \mathrm{~min}$. Primers (Supplemental Data) were purchased from Sangon Biotech (Shanghai, China). Standard procedures were applied for all DNA manipulations (Sambrook et al., 1989).

A 1382 bp product containing the $\mathrm{COM}_{\mathrm{ppsB}}$ fragment was amplified using oligonucleotides ppsB-F and ppsB-R. The resulting product was digested with $S p h \mathrm{I}$ and SalI and cloned into the E. coli expression vector PMD-19 that was digested with the same enzymes to give pCC42. After digestion with SphI and SalI, the fragment was ligated into $\mathrm{pKS} 2$ to give $\mathrm{pKSA} 1$. Based on the 21 bp overlapping region in $\mathrm{M}-\mathrm{F}$ and $\mathrm{M}-\mathrm{R}, \mathrm{pKSA} 1$ was used as template for the subsequent PCR with oligonucleotides M-F and $\mathrm{M}-\mathrm{R}$ to generate point mutations.

Two $600 \mathrm{bp}$ ppsC fragments were amplified using oligonucleotides K-up-F and K-up-R, and K-down-F and K-down-R, respectively. After cloning into the E. coli expression vector PMD-19 and digestion with ClaI, SalI, SalI, and KpnI, the fragments were ligated into $\mathrm{pKS} 2$ to give $\mathrm{pKSK} 1$, which was used as template for PCR with oligonucleotides P1-F and $\mathrm{P} 1-\mathrm{R}$ to gain the $\mathrm{pKSP} 1$ for use in the initial substitution step. Subsequently, $650 \mathrm{bp}$ upstream and downstream gene fragments were amplified by PCR and the target $\mathrm{COM}_{\mathrm{ppC}}^{\mathrm{D}}$ (the donor $\mathrm{COM}$ of ppsC) fragment was combined with the downstream fragment by fusion PCR using the oligonucleotides P2-down1-F and P2-down2-F. The resultant product was digested with SalI and $K p n \mathrm{I}$ and ligated into pKS2 that was also digested with these enzymes, and oligonucleotides P2-up-F and P2-down$\mathrm{R}$ were used to generate $\mathrm{pKSP} 2$. Next, PCR was performed using oligonucleotides $\mathrm{P} 3-\mathrm{F}$ and $\mathrm{P} 3-\mathrm{R}$ and $\mathrm{pKSK} 1$ as template to generate $\mathrm{pKSP} 3$ for permutation in the third step of the procedure. To this end, $650 \mathrm{bp}$ upstream and downstream fragments were amplified using oligonucleotides P4-up-F, P4-up-R, P4-down3-F, and P4-down-R, while a 72 bp fragment of $\mathrm{COM}_{\mathrm{ppsD}}^{\mathrm{D}}$ was amplified using oligonucleotides P4-down1-F and P4-down2-F. After purification, DNA fragments were combined and used as template for PCR amplification with oligonucleotides P4-up-F and P4-down-R, and subsequent cloning into $\mathrm{pKS} 2$ yielded the final disruption vector $\mathrm{pKSP} 4$ (Table S1). The maps of plasmids used to construct the deletion mutant, point mutation and substitution were shown in Figures S3, S4, respectively.

\section{B. subtilis Strain Construction}

Transformations were carried out as described previously (Anagnostopoulos and Spizizen, 1961), and genotypes were verified by PCR. The pKSA1, pKSK1, and pKSP1 plasmids were transformed into B. subtilis $\mathrm{PB} 2-\mathrm{L}$, B. subtilis PB2-LP1 was transformed with $\mathrm{pKSP} 2$, and the resulting 
TABLE 1 | Lipopeptides, retention times, $\mathrm{m} / \mathrm{z}$ values of protonated forms and peptide sequences.

\begin{tabular}{|c|c|c|c|c|c|}
\hline $\begin{array}{l}\text { Approach of COM } \\
\text { changes }\end{array}$ & $\begin{array}{l}\text { Homologues } \\
\text { of peptides }\end{array}$ & RT (min) & Molecular formula & Mass $(\mathrm{m} / \mathrm{z})$ & Peptide sequence \\
\hline \multirow{4}{*}{$\begin{array}{l}\text { Point mutation of donor } \\
\text { ppsB (T7D) }\end{array}$} & A1 & 13.94 & $n=12 ; \mathrm{C}_{45} \mathrm{H}_{74} \mathrm{~N}_{6} \mathrm{O}_{11}$ & 875.5498 & $\beta$-OHFA-ABE \\
\hline & $\mathrm{A} 2$ & 14.15 & $n=13 ; \mathrm{C}_{46} \mathrm{H}_{76} \mathrm{~N}_{6} \mathrm{O}_{11}$ & 889.5688 & Cyclo pentapeptide \\
\hline & A3 & 14.15 & $n=14 ; \mathrm{C}_{47} \mathrm{H}_{78} \mathrm{~N}_{6} \mathrm{O}_{11}$ & 903.5841 & $\mathrm{CH} 3\left(\mathrm{CH}_{2}\right) \mathrm{n} 1 \mathrm{CHOHCH} 2 \mathrm{CO}-\mathrm{Glu}-\mathrm{Orn}-$ \\
\hline & A4 & 14.15 & $n=15 ; \mathrm{C}_{48} \mathrm{H}_{80} \mathrm{~N}_{6} \mathrm{O}_{11}$ & 917.6087 & Tyr-Thr -lle; $n 1=12-15$ \\
\hline \multirow[t]{7}{*}{ Deletion of donor ppsC } & B1 & 13.07 & $n=10 ; \mathrm{C}_{47} \mathrm{H}_{77} \mathrm{~N}_{7} \mathrm{O}_{15}$ & 980.5580 & \\
\hline & B2 & 13.15 & $n=11 ; \mathrm{C}_{48} \mathrm{H}_{79} \mathrm{~N}_{7} \mathrm{O}_{15}$ & 994.5712 & \\
\hline & B3 & 13.20 & $n=12 ; \mathrm{C}_{49} \mathrm{H}_{81} \mathrm{~N}_{7} \mathrm{O}_{15}$ & 1008.5873 & $\beta-O H F A-A B C$ \\
\hline & B4 & 13.68 & $n=13 ; \mathrm{C}_{50} \mathrm{H}_{83} \mathrm{~N}_{7} \mathrm{O}_{15}$ & 1022.6026 & Linear hexapeptide \\
\hline & B5 & 14.15 & $n=14 ; \mathrm{C}_{51} \mathrm{H}_{85} \mathrm{~N}_{7} \mathrm{O}_{15}$ & 1036.6179 & $\begin{array}{l}\mathrm{CH} 3(\mathrm{CH} 2) n 2 \mathrm{CHOHCH}_{2} \mathrm{CO}-\mathrm{Glu}-\mathrm{Orn}-\mathrm{Tyr}-\mathrm{Thr} \text {-Glu- } \\
\text { Val; } \mathrm{n} 2=10-16\end{array}$ \\
\hline & B6 & 14.15 & $n=15 ; \mathrm{C}_{52} \mathrm{H}_{87} \mathrm{~N}_{7} \mathrm{O}_{15}$ & 1050.6338 & \\
\hline & B7 & 14.15 & $n=16 ; \mathrm{C}_{53} \mathrm{H}_{89} \mathrm{~N}_{7} \mathrm{O}_{15}$ & 1064.6493 & \\
\hline \multirow{3}{*}{$\begin{array}{l}\text { the donor of ppsD } \\
\text { replaced with ppsC }\end{array}$} & C1 & 15.63 & $n=11 ; \mathrm{C}_{67} \mathrm{H}_{103} \mathrm{~N}_{11} \mathrm{O}_{20}$ & 1382.7556 & $\beta-O H F A-A B C D$ \\
\hline & $\mathrm{C} 2$ & 15.63 & $n=12 ; \mathrm{C}_{68} \mathrm{H}_{105} \mathrm{~N}_{11} \mathrm{O}_{20}$ & 1396.7715 & Linear nonapeptide \\
\hline & C3 & 15.98 & $n=13 ; \mathrm{C}_{69} \mathrm{H}_{107} \mathrm{~N}_{11} \mathrm{O}_{20}$ & 1410.7876 & $\begin{array}{l}\mathrm{CH}_{3}\left(\mathrm{CH}_{2}\right)_{n 3} \mathrm{CHOHCH}_{2} \mathrm{CO}- \\
\text { Glu-Orn-Tyr-Thr-Glu-Val-Pro-Gln-Tyr; n3 = 11-13 }\end{array}$ \\
\hline \multirow{4}{*}{$\begin{array}{l}\text { the acceptor of ppsB } \\
\text { replaced with ppsC }\end{array}$} & D1 & 12.15 & $\mathrm{n}=10 ; \mathrm{C}_{66} \mathrm{H}_{101} \mathrm{~N}_{11} \mathrm{O}_{20}$ & 1368.7387 & $\beta$-OHFA-ABCD \\
\hline & D2 & 12.33 & $\mathrm{n}=11 ; \mathrm{C}_{67} \mathrm{H}_{103} \mathrm{~N}_{11} \mathrm{O}_{20}$ & 1382.7517 & Linear nonapeptide \\
\hline & D3 & 13.15 & $\mathrm{n}=12 ; \mathrm{C}_{68} \mathrm{H}_{105} \mathrm{~N}_{11} \mathrm{O}_{20}$ & 1396.7667 & $\mathrm{CH}_{3}\left(\mathrm{CH}_{2}\right)_{\mathrm{n} 4} \mathrm{CHOHCH}{ }_{2} \mathrm{CO}-$ \\
\hline & D4 & 13.68 & $\mathrm{n}=13 ; \mathrm{C}_{69} \mathrm{H}_{107} \mathrm{~N}_{11} \mathrm{O}_{20}$ & 1410.7817 & Glu-Orn-Tyr-Thr -Glu-Val -Pro-Gln-Tyr;n4 = 11-14 \\
\hline \multirow{5}{*}{$\begin{array}{l}\text { the donor of } \mathrm{ppsC} \\
\text { replaced with } \mathrm{ppsD}\end{array}$} & E1 & 13.52 & $\mathrm{n}=12 ; \mathrm{C}_{53} \mathrm{H}_{88} \mathrm{~N}_{8} \mathrm{O}_{16}$ & 1093.6393 & \\
\hline & E2 & 13.68 & $\mathrm{n}=13 ; \mathrm{C}_{54} \mathrm{H}_{90} \mathrm{~N}_{8} \mathrm{O}_{16}$ & 1107.6598 & $\beta$-OHFA-ABCE \\
\hline & E3 & 14.15 & $\mathrm{n}=14 ; \mathrm{C}_{55} \mathrm{H}_{92} \mathrm{~N}_{8} \mathrm{O}_{16}$ & 1121.6753 & Linear heptapeptide \\
\hline & E4 & 14.69 & $\mathrm{n}=15 ; \mathrm{C}_{56} \mathrm{H}_{94} \mathrm{~N}_{8} \mathrm{O}_{16}$ & 1135.6871 & $\mathrm{CH}_{3}\left(\mathrm{CH}_{2}\right)_{n 5} \mathrm{CHOHCH}_{2} \mathrm{CO}-\mathrm{Glu}-\mathrm{Orn}-$ \\
\hline & E5 & 14.69 & $\mathrm{n}=16 ; \mathrm{C}_{57} \mathrm{H}_{96} \mathrm{~N}_{8} \mathrm{O}_{16}$ & 1149.7043 & Tyr-Thr-Glu-Ala -lle; n5 = 12-16 \\
\hline \multirow{4}{*}{$\begin{array}{l}\text { Deletion of donor ppsC } \\
\text { and the acceptor of } \\
\text { ppsC replaced with } \\
\text { ppsB }\end{array}$} & $\mathrm{F} 1$ & 17.05 & $\mathrm{n}=12 ; \mathrm{C}_{64} \mathrm{H}_{98} \mathrm{~N}_{10} \mathrm{O}_{16}$ & 1263.7235 & $\beta$-OHFA-ABDE \\
\hline & $\mathrm{F} 2$ & 17.12 & $\mathrm{n}=13 ; \mathrm{C}_{65} \mathrm{H}_{100} \mathrm{~N}_{10} \mathrm{O}_{16}$ & 1277.7412 & Cyclo octapeptide \\
\hline & F3 & 17.68 & $\mathrm{n}=14 ; \mathrm{C}_{66} \mathrm{H}_{102} \mathrm{~N}_{10} \mathrm{O}_{16}$ & 1291.7504 & $\mathrm{CH}_{3}\left(\mathrm{CH}_{2}\right)_{n 6} \mathrm{CHOHCH}_{2} \mathrm{CO}-\mathrm{Glu}$-Orn \\
\hline & F4 & 18.06 & $\mathrm{n}=15 ; \mathrm{C}_{67} \mathrm{H}_{104} \mathrm{~N}_{10} \mathrm{O}_{16}$ & 1305.7682 & 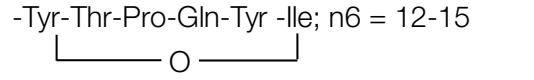 \\
\hline
\end{tabular}

R-OHFA-ABE, The lipopeptides produced by NRPS complex assembly line ppsA, ppsB, and ppsE; $\beta$-OHFA-ABC, The lipopeptides produced by NRPS complex assembly line ppsA,

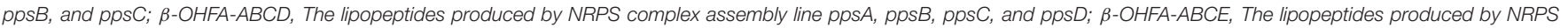
complex assembly line ppsA, ppsB, ppsC, and ppsE; $\beta$-OHFA-ABDE, The lipopeptides produced by NRPS complex assembly line ppsA, ppsB, ppsD, and ppsE.

strain was transformed with pKSP3 and pKSP4, generating B. subtilis mutants PB2-LA1 $\left(\mathrm{COM}_{\mathrm{ppsB}}^{\mathrm{D}} \mathrm{T}:: \mathrm{D}\right)$, PB2-LK1 $\left(\triangle \mathrm{COM}_{\mathrm{ppsC}}^{\mathrm{D}}\right), \quad \mathrm{PB} 2-\mathrm{LP} 1 \quad\left(\mathrm{COM}_{\mathrm{pps}}^{\mathrm{A}}:: \mathrm{COM}_{\mathrm{ppsB}}^{\mathrm{A}}\right), \quad \mathrm{PB} 2-\mathrm{LP} 2$ $\left(\mathrm{COM}_{\mathrm{ppsC}}^{\mathrm{A}}:: \mathrm{COM}_{\mathrm{ppsB}}^{\mathrm{A}}\right.$ and $\left.\mathrm{COM}_{\mathrm{pps}}^{\mathrm{D}}:: \mathrm{COM}_{\mathrm{ppsC}}^{\mathrm{D}}\right)$, PB2-LP3 $\left(\mathrm{COM}_{\mathrm{ppsC}}^{\mathrm{A}}:: \mathrm{COM}_{\mathrm{pps}}^{\mathrm{A}}, \mathrm{COM}_{\mathrm{pps}}^{\mathrm{D}}: \mathrm{COM}_{\mathrm{pps}}^{\mathrm{D} C}\right.$ and $\mathrm{COM}_{\mathrm{pps}}^{\mathrm{A}}::$ $\left.\mathrm{COM}_{\mathrm{ppsC}}^{\mathrm{A}}\right)$, and PB2-LP4 $\left(\mathrm{COM}_{\mathrm{ppsC}}^{\mathrm{A}}:: \mathrm{COM}_{\mathrm{ppsB}}^{\mathrm{A}}, \mathrm{COM}_{\mathrm{ppsD}}^{\mathrm{D}}::\right.$ $\mathrm{COM}_{\mathrm{ppsC}}^{\mathrm{D}}, \mathrm{COM}_{\mathrm{pps} \mathrm{A}}^{\mathrm{A}}: \mathrm{COM}_{\mathrm{ppsC}}^{\mathrm{A}}$ and $\left.\operatorname{COM}_{\mathrm{ppsC}}^{\mathrm{D}}:: \mathrm{COM}_{\mathrm{ppsD}}^{\mathrm{D}}\right)$. The pKSK1 and pKSP1 plasmids were transformed into $B$. subtilis $\mathrm{PB} 2-\mathrm{L}$ in two steps to give $B$. subtilis mutants PB2-LK1 $\left(\Delta \mathrm{COM}_{\mathrm{ppsC}}^{\mathrm{D}}\right)$ and PB2-LKP1 $\left(\Delta \mathrm{COM}_{\mathrm{pps}}^{\mathrm{D}}, \mathrm{COM}_{\mathrm{ppsC}}^{\mathrm{A}}::\right.$ $\mathrm{COM}_{\mathrm{ppsB}}^{\mathrm{A}}$ ) (Table S1).

\section{Production of Antimicrobial Extracts}

Modified strains were cultivated in Landy medium $(20 \mathrm{~g} / \mathrm{L}$ glucose, $1 \mathrm{~g} / \mathrm{L}$ yeast extract, $5 \mathrm{~g} / \mathrm{L} \mathrm{L}$-glutamic acid, $1 \mathrm{~g} / \mathrm{L} \quad \mathrm{KH}_{2} \mathrm{PO}_{4}, \quad 0.16 \mathrm{mg} / \mathrm{L} \quad \mathrm{CuSO}_{4}, \quad 0.5 \mathrm{~g} / \mathrm{L} \quad \mathrm{MgSO}_{4} \cdot 7 \mathrm{H}_{2} \mathrm{O}$, $0.15 \mathrm{mg} / \mathrm{L} \mathrm{FeSO}_{4}, 0.5 \mathrm{~g} / \mathrm{L} \mathrm{KCl}, 5 \mathrm{mg} / \mathrm{L} \mathrm{MnSO}_{4} \cdot \mathrm{H}_{2} \mathrm{O}, \mathrm{pH} 7.0$ ) at $33^{\circ} \mathrm{C}$ in a rotary shaker at $180 \mathrm{rpm}$ for 3 days to produce antimicrobial substances (Landy et al., 1947; Deng et al., 2011b). Antimicrobial extracts were obtained using an organic solvent (methanol) extraction method.

\section{Product Formation Assays}

The crude methanol extract was fractioned by the high resolution LC-ESI-MS and LC-ESI-MS/MS analysis, which was performed 
with a Thermo Finnigan Surveyor-LCQ DECA XP Plus (Thermo Electron Corporation, San Jose, CA, USA). The flow rate was maintained at $0.2 \mathrm{~mL} / \mathrm{min}$ with a gradient of $22 \mathrm{~min}(0-95 \%$, $\mathrm{vol} / \mathrm{vol}$ acetonitrile for $18 \mathrm{~min}$ and $95-5 \%$, vol/vol acetonitrile for $4 \mathrm{~min}$ ). The electrospray needle was operated at a spray voltage of $5 \mathrm{kV}$, a capillary voltage of $32 \mathrm{~V}$ and a capillary temperature of $300^{\circ} \mathrm{C}$. For the $\mathrm{HCD}$ experiment, helium was used as the collision gas and the collision energy was set at $35 \%$. Elution was monitored by UV detection at $214 \mathrm{~nm}$ (Mootz et al., 2000; Deng et al., 2011b).

\section{Determination of Antimicrobial Activity}

The linear products were synthetized by KareBay BioChem, Inc. Antimicrobial activity was evaluated by determining MIC values using the standard broth microdilution method (Nedorostova et al., 2009) with some modifications. Tested microorganisms were incubated at 37 or $30^{\circ} \mathrm{C}$ to approximately $10^{6}-10^{7} \mathrm{CFU} / \mathrm{ml}$ in lysogeny broth (LB) medium. Serial dilutions of antimicrobial compounds were prepared to obtain final concentrations of $1000,500,250,125,62.5,31.25,15.63$, and $7.81 \mu \mathrm{g} / \mathrm{ml}$ in LB or PDA medium. The ability of cyclic products strains to inhibit the growth of various indicator organisms was determined qualitatively by agar-well diffusion method (Deng et al., 2011a). Plates were incubated for up to 24 (bacteria) and $48 \mathrm{~h}$ (fungi) before the antimicrobial activities were determined (Oh et al., 2011). Samples incubated without antimicrobials were used as controls.

\section{RESULTS}

\section{Influence of a ppsB Donor Point Mutation on Plipastatin Synthesis}

To demonstrate the biocombinatorial potential of COM domains, we investigated crosstalk between $\mathrm{ppsB}$ and $\mathrm{ppsC}$ modules through point mutations. Seven positions in $\mathrm{COM}_{\mathrm{pps} B}^{\mathrm{D}}$ (Figure 1C) were mutated as follows: W1K, S2T, A3L, T7D, E9K, D10S, and G12S. We evaluated the impact of $\mathrm{COM}_{\mathrm{pps}}^{\mathrm{D} B}$ point mutants on lipopeptide biosynthesis.

Based on the high-resolution LC-ESI-MS spectra, all the point mutants did not produce novel lipopeptides (data not shown) except for the T7D mutation. In high-resolution ESI-MS spectra, a series of charge $1(z=1)$ molecular ions with $\mathrm{m} / z$ values at $875.5488,889.5644,903.5801$, and 917.5963 (Figure 2A) led us to predict the formation of a $\beta-\mathrm{OH}$ fatty acid ( $\beta$-OHFA)-ABE product. And the predicted formula was $\mathrm{C}_{46} \mathrm{H}_{76} \mathrm{~N}_{6} \mathrm{O}_{11}(\mathrm{ppm}=4.831)$ at $\mathrm{m} / z$ 889.5644. Using the $\mathrm{HCD}-\mathrm{MS} / \mathrm{MS}$ spectrum of the precursor ion $[\mathrm{M}+\mathrm{H}]^{+}$at $\mathrm{m} / \mathrm{z}$ of 889.5644 (Figure 2B), -b and -y productions (Pathak et al., 2013) were assigned (Figure 2C), which enabled us to infer the sequence cyclo-[ $\beta$-OHFA-Glu-Orn- Tyr-Thr-Ile]. The formula $\left(\mathrm{C}_{46} \mathrm{H}_{76} \mathrm{~N}_{6} \mathrm{O}_{11}\right)$ was consistent with the results of mass spectrometry (Table 1). The molecular mass ions at $\mathrm{m} / \mathrm{z}$ $875.5488,903.5801$, and 917.5963 were found to be derived from a $\beta$-OHFA chain variant at $m / z 889.5644$ sharing the same peptide sequence (Figure 1D), based on the fragment ion profile obtained by high-resolution HCD-MS/MS. These lipopeptide precursor ions with a $14 \mathrm{Da}$ (Yang et al., 2015) mass difference from $\mathrm{m} / \mathrm{z} 889.5644$ ion were assigned as new pentapeptide variants differing only in $\beta$-OHFA chain length.

The T7D mutation resulted in a loss in the ability of the $\mathrm{COM}^{\mathrm{D}}$ domain to form a productive complex with its native partner $\mathrm{COM}_{\mathrm{ppsB}}^{\mathrm{A}}$ (the acceptor $\mathrm{COM}$ of ppsB). However, at the same time, ppsB point mutant gained the ability to interact with the ppsE. Meanwhile, a novel NRPS complex assembly line ppsA, ppsB and ppsE was formed. This indicated that the mutation of threonine in the donor COM domain of ppsB to aspartic acid was sufficient to transfer selectivity from the cognate acceptor COM toward the noncognate accepter COM of ppsD, and highlights the importance of the threonine residue at this position in protein-protein communication.

\section{Influence of ppsC Donor Deletion Mutant on Plipastatin Synthesis}

The deletion of ppsC donor on the ability to interact with the partner elongation module ppsD was investigated in vivo (Figure 1C). As shown in Table 1, the high-resolution ESI-MS revealed a series of charge $1(z=1)$ ions with $\mathrm{m} / z$ at 980.5560, 994.5712, 1008.5873, 1022.6026, 1036.6179, 1050.6338, and 1064.6493 (Figure 3A) that eluted with a retention time between 13.07 and $14.15 \mathrm{~min}$. And the predicted formula was $\mathrm{C}_{49} \mathrm{H}_{81} \mathrm{~N}_{7} \mathrm{O}_{15}(\mathrm{ppm}=0.673)$ at $m / z$ 1008.5873. And the high-resolution HCD-MS/MS spectrum of the precursor ion (Figure 3B) was analyzed, and $-\mathrm{b}$ and $-\mathrm{y}$ ions were consistent with a linear [ $\beta$-OHFA-Glu-Orn- Tyr-Thr-Glu-Val] peptide (Figure 3C), which lacked four amino acid residues (Pro, Gln, Tyr, and Ile) that are present in plipastatin. The formula of linear peptide was in accord with the MS spectra analysis. Furthermore, other molecular ions were clearly derived from this peptide moiety, and the $14 \mathrm{Da}$ differences again indicated varying chain length of the $\beta$-OHFA (Figure 1D). The $\mathrm{COM}_{\mathrm{ppsC}}^{\mathrm{D}}$ deletion largely resulted in a loss in the ability of the $\mathrm{COM}^{D}$ domain to form a productive complex with its native partner $\mathrm{COM}_{\mathrm{ppsC}}^{\mathrm{A}}$. The deletion mutant was completely inactive in a product formation assay with ppsD, resulting in formation of the novel NRPS complex assembly line ppsA, ppsB, and ppsC.

\section{Influence of Interchangeabilities in COM Domain on Plipastatin Synthesis}

Indeed, deletion of the donor module ppsC prevents plipastatin biosynthesis. However, the inability of mutant systems to synthesize plipastatin and the formation of novel products is due to either the loss of protein-protein interaction between donor and acceptor NRPS partners, or inactivity of donor modules causing by the deletion of the most C-terminal amino acid residues.

To challenge these potential explanations, crosstalk experiments were performed, which confirmed that members of the compatible pairs between ppsB and ppsC, ppsC and ppsD, as well as ppsD and ppsE were interchangeable in vivo. First, acceptor ppsC was initially swapped with ppsB, and donor ppsD was subsequently substituted with donor ppsC. Next, acceptor ppsB was mutated to acceptor ppsC, and donor ppsC was replaced by donor ppsD. Plipastatin was observed in the 


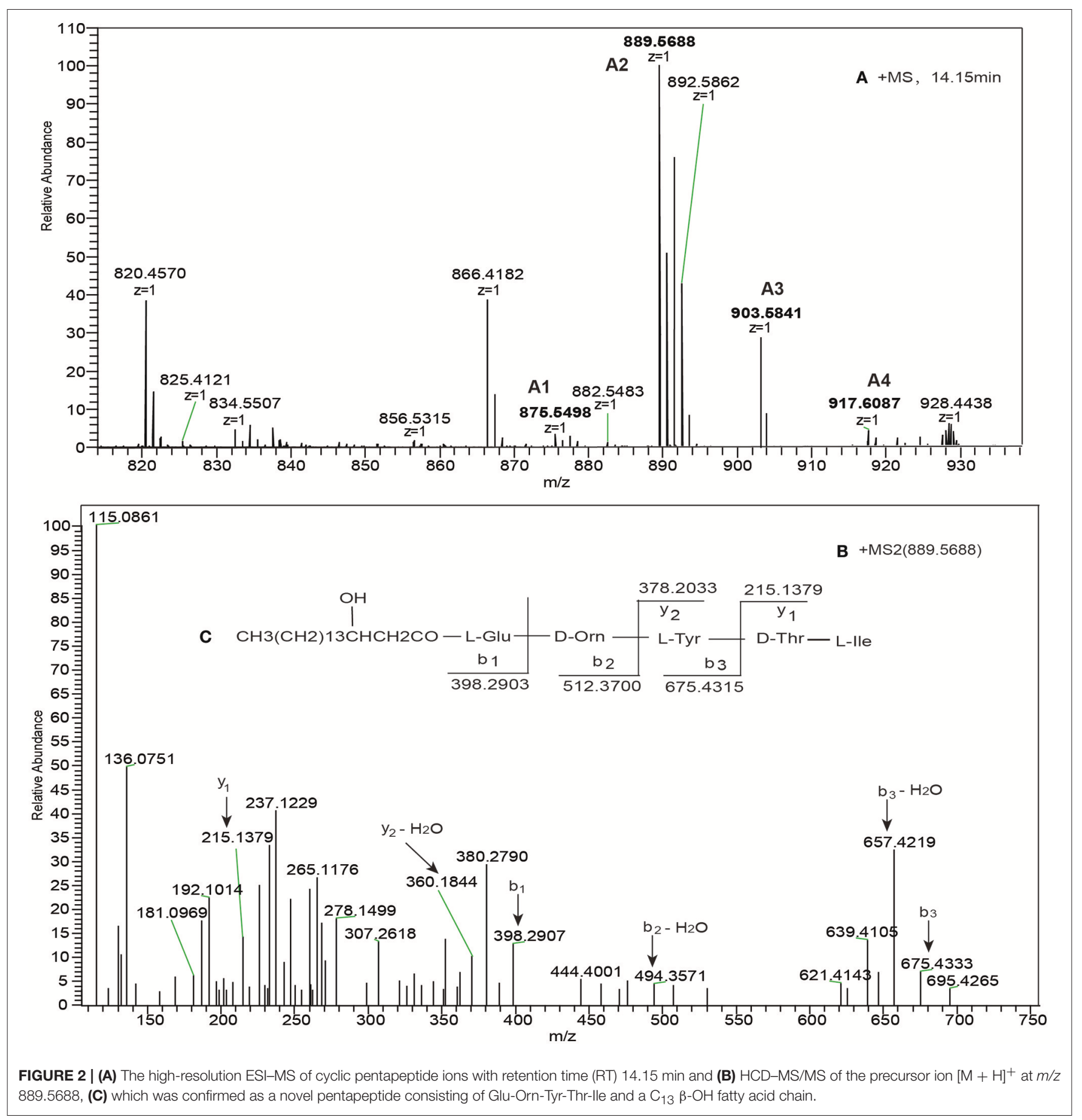

methanolic extract when acceptor ppsC was replaced by acceptor ppsB (data not shown), and the anticipated novel product was not formed. However, when $\mathrm{COM}_{\mathrm{ppsD}}^{\mathrm{D}}$ was replaced by $\mathrm{COM}_{\mathrm{ppsC}}^{\mathrm{D}}$, the high-resolution ESI-MS gave the charge 1 molecular mass ions of $\mathrm{m} / z$ 1382.7556, 1396.7715, and 1410.7876 (Figure 4A), which were assigned as hydrogen adducts of corresponding protonated novel nonapeptide ions. The charge $2(z=2)$ of the mass ions was 691.8796, 698.8879, and 705.8953, which verified the predicted formula was $\mathrm{C}_{68} \mathrm{H}_{105} \mathrm{~N}_{11} \mathrm{O}_{20}$ (ppm $=4.333$ ).
In order to confirm the assignments, the $\mathrm{m} / z \quad 1396.7715$ ion was subjected to the high-resolution HCD-MS/MS (Figure 4B), and the $-\mathrm{y}$ ion series at $m / z 736.3506\left(-\mathrm{H}_{2} \mathrm{O}\right.$, $718.3523) \rightarrow 508.2406 \rightarrow 407.1911 \rightarrow 310.1407 \rightarrow 181.0986$ was consistent with Glu-Val-Pro-Gln-Tyr from the N-terminus, while the $-b$ ion series $762.4486 \rightarrow 661.4158 \rightarrow 498.3586 \rightarrow$ 384.2732 suggested that the precursor ion possessed a Glu-OrnTyr-Thr at the C-terminus and a C12 $\beta-\mathrm{OH}$ fatty acid that lacked the Ile residue present in plipastatin, and the fragmentation 

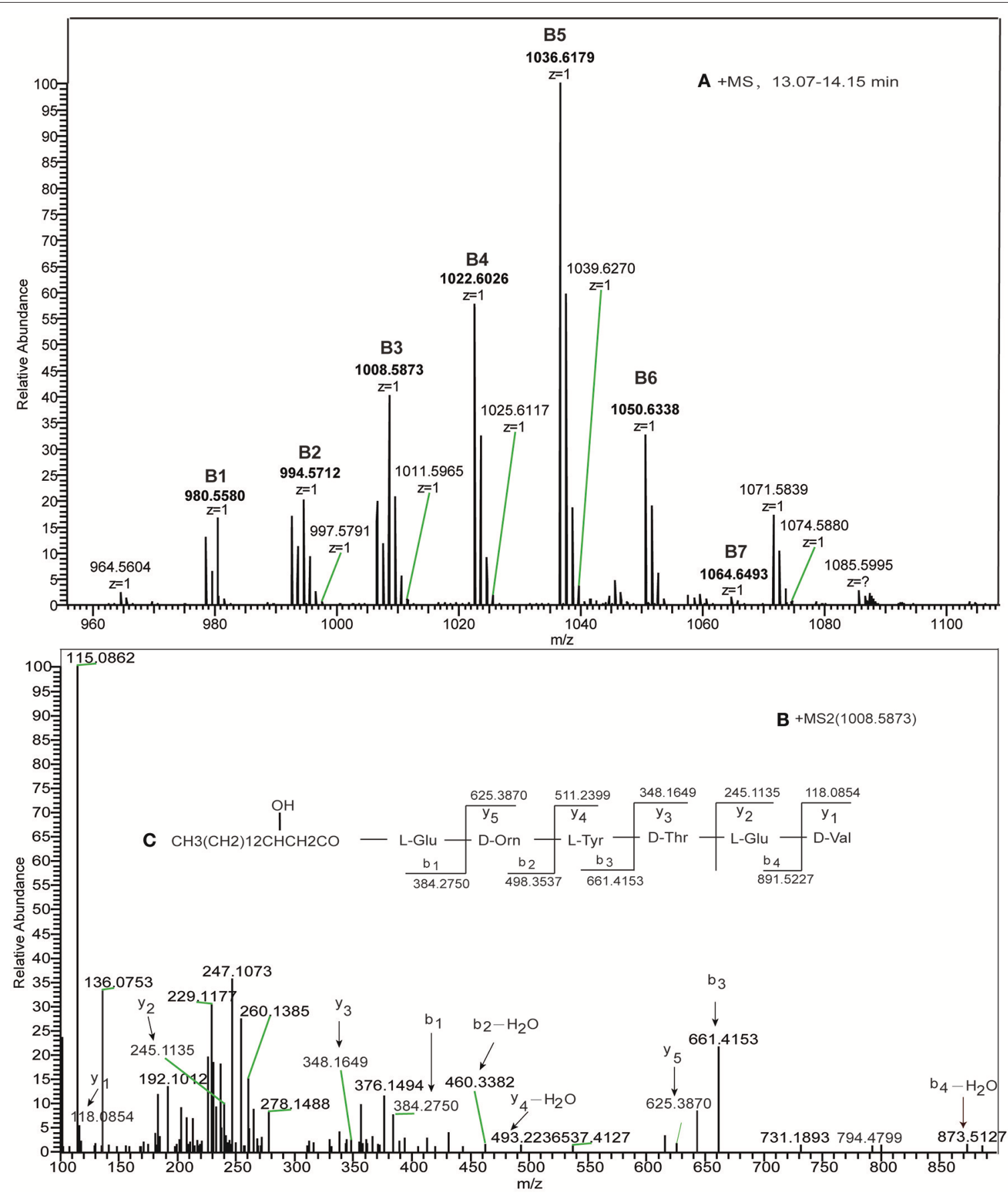

FIGURE 3 | (A) The high-resolution ESI-MS of linear hexapeptide ions with RT in the range 13.07-14.15 min and (B) HCD-MS/MS of the precursor ion [M + H] + at $\mathrm{m} / \mathrm{z}$ 1008.5873, (C) which was confirmed as a novel hexapeptide consisting of Glu-Orn-Tyr-Thr-Glu-Val and a $\mathrm{C}_{12} \beta$-OH fatty acid chain.

pattern for the entire $\mathrm{m} / \mathrm{z} 1396.7715$ is consistent with MS/MS analysis (Figure 4C). Again, other molecular mass ions differing by $14 \mathrm{Da}\left(-\mathrm{CH}_{2}-\right)$ were clearly derived from the same peptide sequence but with $\mathrm{C} 11$ and $\mathrm{C} 13 \beta-\mathrm{OH}$ fatty acids, respectively (Table 1, Figure 1D). This indicated that the donor of ppsD loss the ability of forming a productive complex with its native partner, and resulting the formation of the NRPS complex assembly line ppsA, ppsB, ppsC and ppsD.
Subsequent mutation of acceptor ppsB to acceptor ppsC was predicted to result in a product with one further modification. The charge $1(z=1)$ molecular mass ions at $\mathrm{m} / z$ 1368.7387, 1382.7517, 1396.7667, and 1410.7817 and the charge $2(z=2)$ of the mass ions at $\mathrm{m} / z$ 684.8743, 691.8776, 698.8860 , and 705.8932 were observed in the high-resolution ESI-MS spectrum (Figure S6A), which verified the predicted formula at $m / z 1396.7667$ was $\mathrm{C}_{68} \mathrm{H}_{105} \mathrm{~N}_{11} \mathrm{O}_{20}(\mathrm{ppm}=4.181)$. 

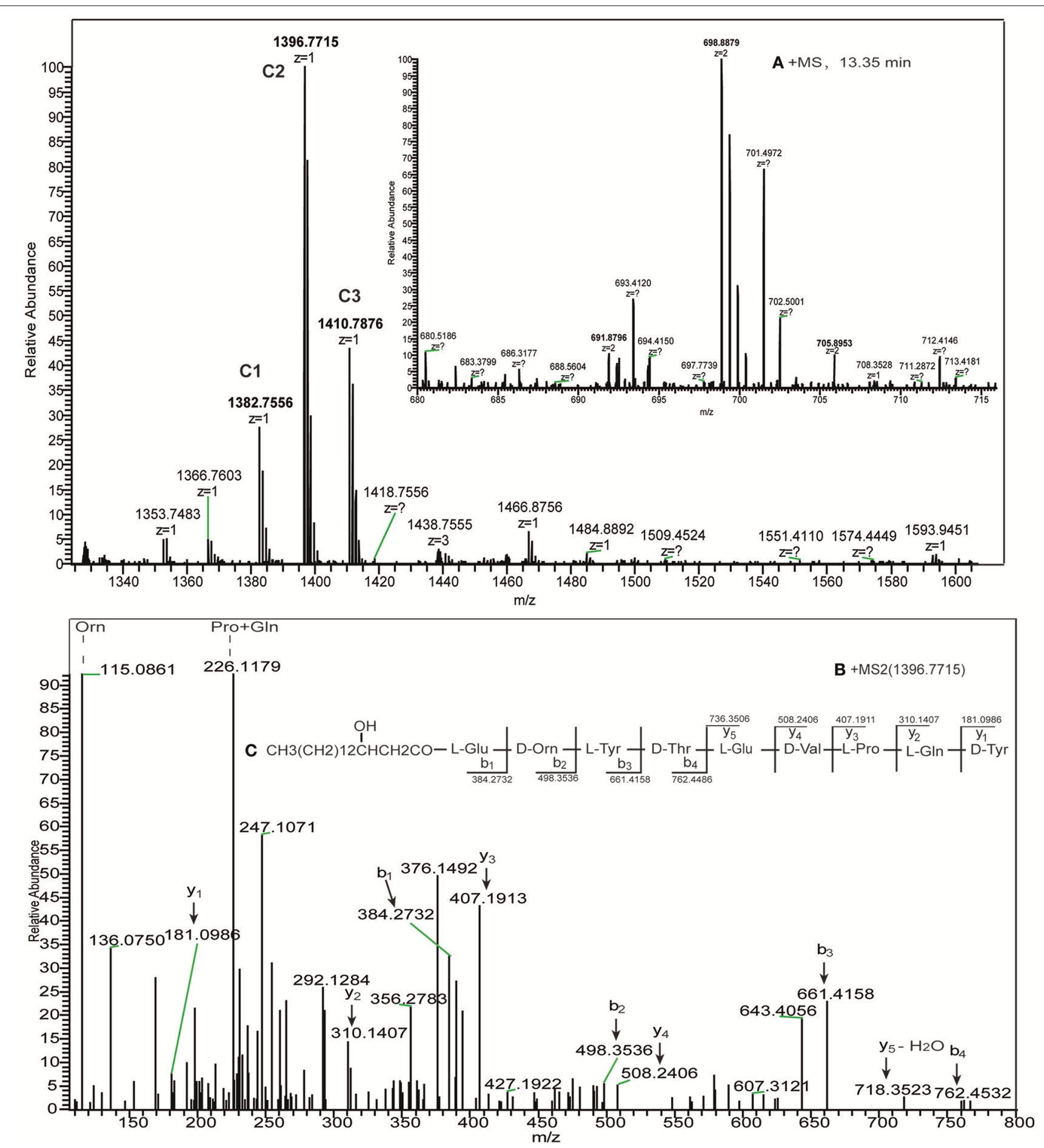

FIGURE 4 | (A) The high-resolution ESI-MS of linear nonapeptide ions with RT 13.35 min and (B) HCD-MS/MS of the precursor ion [M + H] ${ }^{+}$at $m / z$ 1396.7715, (C) which was confirmed as a novel nonapeptide consisting of Glu-Orn-Tyr-Thr-Glu-Val-Pro- Gln-Tyr and a $\mathrm{C}_{12} \beta-\mathrm{OH}$ fatty acid chain.

The high-resolution HCD-MS/MS fragmentation of the $\mathrm{m} / \mathrm{z}$ 1396.7667 ion (Figure S6B) yielded a series of -b fragment ions at $\mathrm{m} / \mathrm{z} 891.5045762 .4468 \rightarrow 661.4145 \rightarrow 498.3531 \rightarrow 384.2725$ and $-\mathrm{y}$ fragment ions at $\mathrm{m} / \mathrm{z} 736.3506\left(-\mathrm{H}_{2} \mathrm{O}, 718.3517\right) \rightarrow 508.2404 \rightarrow$ $407.1911 \rightarrow 310.1393 \rightarrow 181.0977$ that were consistent with hydrogen adducts of a $\mathrm{C} 12 \beta-\mathrm{OH}$ FA and an nonapeptide with the sequence Glu-Orn-Tyr-Thr-Glu-Val- Pro-Gln- Tyr that is the same as that obtained with the modification described above, and is also lacking the Ile residue comparing the original product plipastatin. The result showed that the NRPS complex 
generated the assembly line ppsA, ppsB, ppsC, and ppsD. Finally, $\mathrm{COM}_{\mathrm{ppsB}}^{\mathrm{D}}$ was replaced with $\mathrm{COM}_{\mathrm{pps}}^{\mathrm{D}}$, this caused the disability of $\mathrm{COM}_{\mathrm{ppsB}}^{\mathrm{D}}$ operon and generation of $\mathrm{COM}_{\mathrm{ppsB}}^{\mathrm{D}}$ mutated to $\mathrm{COM}_{\mathrm{ppsD}}^{\mathrm{D}}$ as expected. The high-resolution ESI-MS spectrum again included hydrogen adduct charge $1(z=1)$ mass ions differing by multiples of $14 \mathrm{Da}$ that eluted between 13.52 and $14.69 \mathrm{~min}$ (Figure 5A). The formula of the $[\mathrm{M}+\mathrm{H}]^{+}$ ion at $m / z 1107.6598$ was $\mathrm{C}_{54} \mathrm{H}_{90} \mathrm{~N}_{8} \mathrm{O}_{16}(\mathrm{ppm}=3.553)$ with the mass spectrum analysis. The high-resolution HCD-MS/MS fragmentation of $m / z 1107.6598$ ion eluting at $13.68 \mathrm{~min}$ resulted in $-\mathrm{b}$ and $-\mathrm{y}$ ion assignments (Figure 5C) consistent with a linear heptapeptide with a linear $\mathrm{C} 13 \beta-\mathrm{OH}$ FA and the sequence Glu-Orn-Tyr-Thr-Glu-Ala-Ile (Figure 5B). This sequence was produced by the NRPS complex assembly line ppsA, ppsB, ppsC,
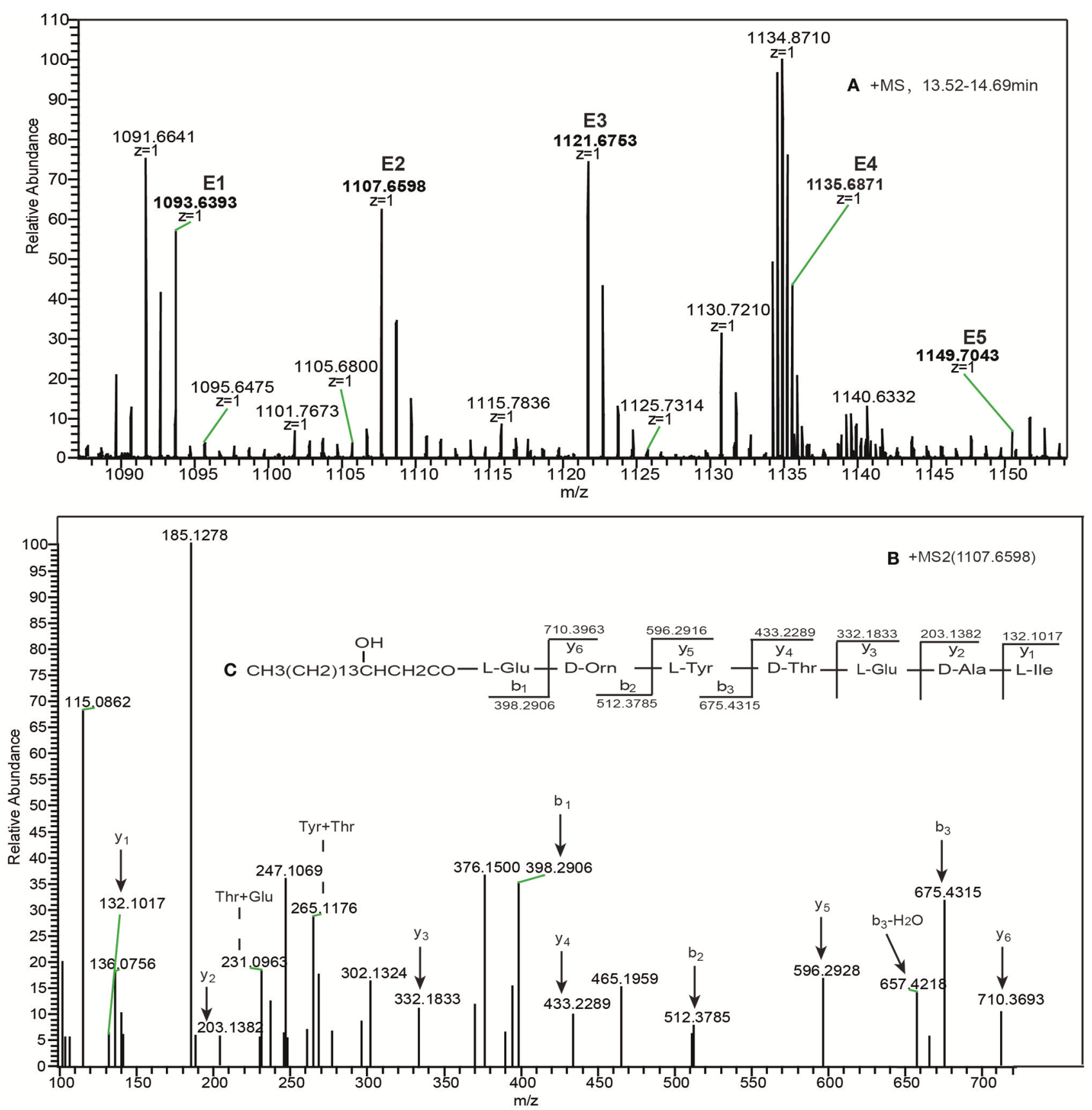

FIGURE 5 | (A) The high-resolution ESI-MS of linear heptapeptide ions eluted with RT in the range 13.52-14.69 min and (B) HCD-MS/MS of the precursor ion [M + $\mathrm{H}^{+}$at $m / z$ 1107.6598, (C) which was confirmed as a novel heptapeptide consisting of Glu-Orn-Tyr-Thr-Glu-Ala-lle and a $\mathrm{C}_{13} \beta$-OH fatty acid chain. 
and ppsE, and lacks three amino acid residues (Pro, Gln and Tyr) that are present in plipastatin. Other linear heptapeptides identified in this study are summarized in Table 1, Figure 1D. Experiments unequivocally confirmed that the acceptor modules did not contribute to the formation of novel products, however, all tested donor modules were equally able to change the native system synthesizing plipastatin.

\section{Influence of Combined Deletion and Substitution of COM Domains on Plipastatin Synthesis}

The second experiment demonstrated that the ppsC module could not couple with the next ppsD module following deletion of the ppsC donor. However, when the partner donor was present, altering the acceptor module had no effect on the formation of novel lipopeptides in the permutation experiment. We therefore decided to investigate whether the acceptor module retains the ability to interact when its partner donor module is deleted. The donor of ppsC was first deleted, and the acceptor of ppsC was then substituted with the acceptor of ppsB (Figure 1C). The highresolution ESI-MS analysis of the resulting product gave a charge $1(z=1)$ molecular mass ion series of $m / z 1263.7235,1277.7412$, 1291.7504, and 1305.7682 (Figure 6A) that corresponded with hydrogen adducts of ions derived from a novel cyclic octapeptide. The predicted formula was $\mathrm{C}_{65} \mathrm{H}_{100} \mathrm{~N}_{10} \mathrm{O}_{16}(\mathrm{ppm}=1.132)$ at $\mathrm{m} / z$ 1277.7412. The high-resolution HCD-MS/MS fragmentation of the $\mathrm{m} / z 1277.7412$ ion (Figure 6B) yielded a $-\mathrm{y}$ ion series at $m / z \quad 102.0553 \rightarrow 766.3765 \rightarrow 881.4631$ from the N-terminus, and $\mathrm{a}-\mathrm{b}$ ion series at $\mathrm{m} / z \quad 226.1178 \rightarrow 389.4315 \rightarrow 502.2661$ $\rightarrow 398.2906 \rightarrow 512.3785$ from the C-terminus, consistent with a cyclic Glu-Orn-Tyr- Thr-Pro-Gln-Tyr-Ile peptide and a C13 $\beta-\mathrm{OH}$ fatty acid lacking Glu and Ala/Val amino acid residues that are present in plipastatin and the fragmentation pattern is illustrated in Figure 6C. Again, other molecular mass ions (Table 1, Figure 1D) differing by $14 \mathrm{Da}\left(-\mathrm{CH}_{2}-\right)$ were derived from the same peptide but with $\mathrm{C} 11, \mathrm{C} 12$, and $\mathrm{C} 14 \beta-\mathrm{OH}$ fatty acids. This indicated that a novel NRPS complex assembly line ppsA, ppsB, ppsD and ppsE directed the production of cyclic octapeptide.

Deletion of donor of ppsC largely abrogated the ability of the $\mathrm{COM}^{\mathrm{D}}$ domain to form a productive complex with its native partner $\mathrm{COM}_{\mathrm{pps}}^{\mathrm{A}}$, but formation of plipastatin was not affected when the acceptor of ppsC was substituted with the acceptor of ppsB. However, the including of both modifications mutant resulted in the ability of ppsB to interact with the ppsC acceptor $\left(\mathrm{COM}_{\mathrm{pps}}^{\mathrm{A}}\right)$. Therefore, the acceptor module retained selectivity when its partner donor module was deleted.

\section{Antimicrobial Activity}

The antimicrobial activity of the linear lipopeptide products was tested against one Gram-positive bacteria, one Gram-negative bacteria and five fungi using a standard dilution approach. The lipopeptides exhibited antimicrobial activity against five of the fungal species at a contention of $31.25-125 \mu \mathrm{g} / \mathrm{ml}$ (Table 2). Interestingly, the novel lipopeptides inhibited both tested bacteria. Penicillium notatum exhibited the least resistance against linear heptapeptide and hexapeptide compared with all fungi, showing a MIC of $31.25 \mu \mathrm{g} / \mathrm{ml}$, which was the value of the linear heptapeptide against Aspergillus ochraceus. The MIC values of all linear lipopeptides against Escherichia coli and Staphylococcus aureus were much higher than against the fungi, and the MIC values were, respectively, 250 and $500 \mu \mathrm{g} / \mathrm{ml}$. The cyclic lipopeptides exhibited the inhibitory activity as shown in Figure S7.

\section{DISCUSSION}

Based on the characterization of NRPS systems, each of the large modular enzymes is deemed responsible for the incorporation of a monomeric precursor into a specific amino acid (Walsh, 2002; Schwarzer et al., 2003). In multienzymatic NRPS complexes, synthesis by most known NRP assembly lines requires appropriate communication between partner enzymes including A-PCP minimal modules (Schneider et al., 1998), C-A-PCP elongation modules (Mootz et al., 2002), A domains (Eppelmann et al., 2002), and translocation of the terminal, product-releasing Te domains (de Ferra et al., 1997). A recent study has examined the interaction between NRPS modules by introducing the photocrosslinking unnatural amino acidBpF (Chin et al., 2002) into aminimal, dimodular NRPS system. Further, the crosslinks were Photocrosslinked and mapped of by MS (Dehling et al., 2016). In addition, protein-protein communication is controlled by the interplay between linker (COM) domains that comprise only 20-30 or 15-25 amino acid residues, and that are located at the $\mathrm{C}$ and $\mathrm{N}$ termini between NRPS enzyme modular domains (Hahn and Stachelhaus, 2004). The selectivity provided by different sets of compatible $\mathrm{COM}^{\mathrm{D}}$ and $\mathrm{COM}^{\mathrm{A}}$ domains results in NRPS complexes that utilize defined biosynthetic templates and synthesize specific peptide products (Hahn and Stachelhaus, 2004, 2006).

In the present study, we investigated the selectivity of COM domains by direct reprogramming of the plipastatin biosynthetic complex, and achieved a biocombinatorial synthesis of new lipopeptides possessing significant antimicrobial activity. Novel lipopeptides sequences were identified by the structure of plipastatin (Deleu et al., 2008) coupled with HCD-MS/MS fragmentation (Pathak et al., 2013). In the first part of the study, the amino acid substitutions can be classified into four groups: (i) conservative exchanges between hydrophobic amino acids (A3L) and polar uncharged residues (S2T and G12S), (ii) substitution of a hydrophobic with a polar residue (W1K), (iii) exchange of a polar uncharged residue for a negatively charged residue (T7D), and (iv) substitution of a polar negatively charged residue with a polar positively charged (E9K) or uncharged (D10S) amino acid. The key residues that mediate the interaction between donor ppsB and acceptor ppsC COM domains were mutated, and the resultant NRPS system was able to form a novel assembly line (ppsA/ppsB/ppsE) that could synthesize lipopentapeptides. Indeed, a Thr-to-Asp mutation resulted in a series of homologous shortened pentapeptide products (Table 1). The previous research demonstrated that the selective 

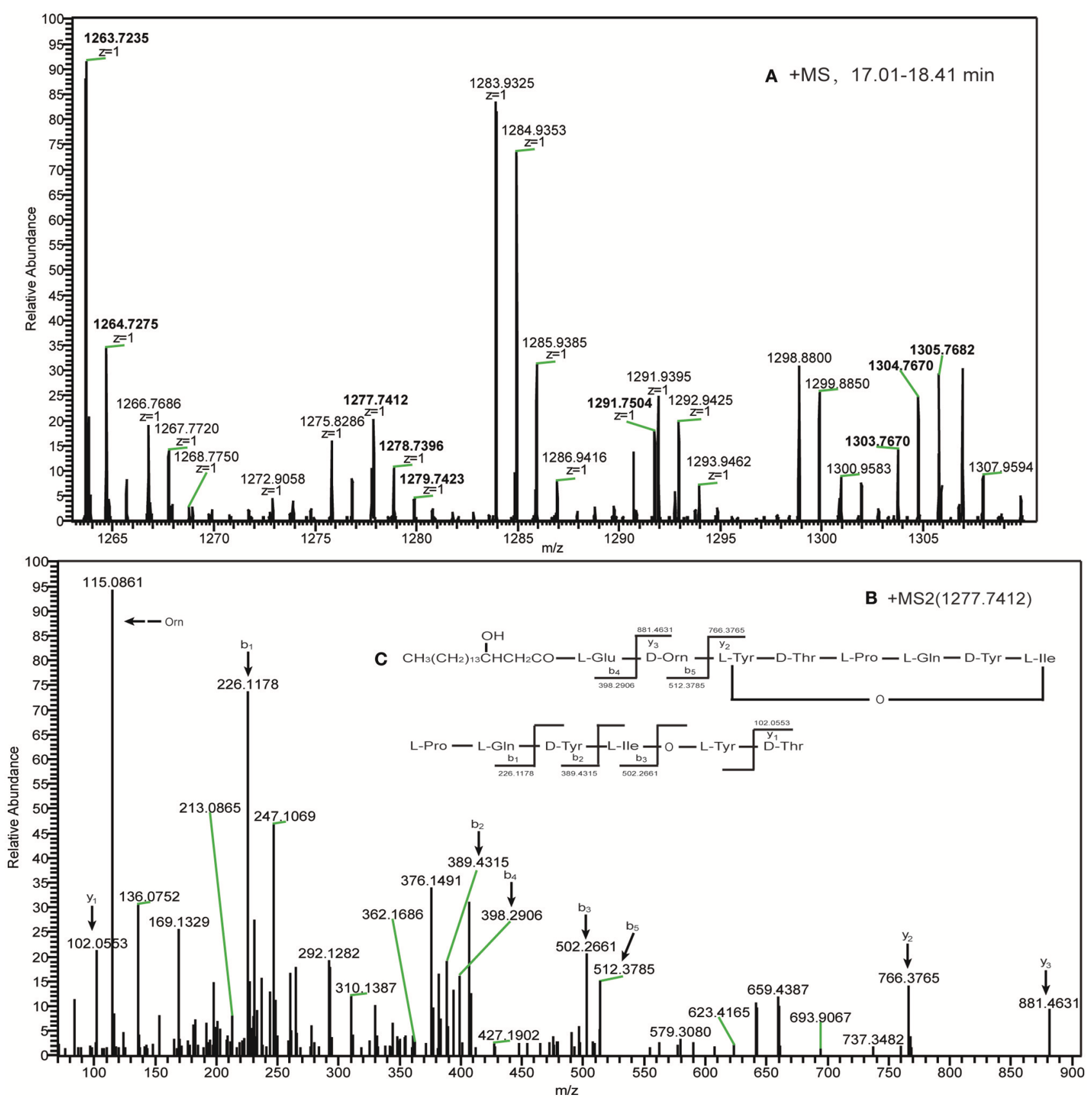

FIGURE 6 | (A) The high-resolution ESI-MS of cyclic octapeptide ions with RT in the range 17.01-18.41 min and (B) HCD-MS/MS of the precursor ion [M + H $]^{+}$at $\mathrm{m} / \mathrm{z}$ 1277.7412, (C) which was confirmed as a novel cyclic octapeptide consisting of Glu-Orn-Tyr-Thr-Pro-Gln-Tyr-Ile and a $\mathrm{C}_{13} \beta$-OH fatty acid chain.

communication is predominantly established by polar and/or electrostatic interactions in tyrocidine NRPS complex (Hahn and Stachelhaus, 2006). However, the substitution of a hydrophobic with a polar residue $(\mathrm{W} 1 \mathrm{~K})$ did not change the selectivity. Therefore, the electrostatic interactions might play a key role in the selective communication. This approach can therefore be used to identify key residues that are important for maintaining (or preventing) the interaction between $\mathrm{COM}^{\mathrm{D}}$ and $\mathrm{COM}^{\mathrm{A}}$ in NRPSs. Deletion of the ppsC donor prevented selectivity of the acceptor of ppsC, and resulted in a novel assembly line (ppsA/ppsB/ppsC) that synthesized a lipohexapeptide. It was also demonstrated that the $\mathrm{COM}^{\mathrm{A}}$ domain alone is insufficient for interacting with its upstream partner enzyme in the enzyme complex with specificity (Cheng et al., 2016). We next questioned whether both the donor and acceptor COM domains influence the selectivity by switching the acceptors of ppsC and ppsB. The differences between respective COM domain pairs were minimal (Figure S2) (Linne et al., 2003), and the mutation of acceptor 
TABLE 2 | Minimum inhibitory concentration (MIC) of lipopeptides against fungal species $(\mu \mathrm{g} / \mathrm{mL})$.

\begin{tabular}{lccc}
\hline $\begin{array}{l}\text { Fungal } \\
\text { species }\end{array}$ & $\begin{array}{c}\text { Linear } \\
\text { hexapeptide }\end{array}$ & $\begin{array}{c}\text { Linear } \\
\text { nonapeptide }\end{array}$ & $\begin{array}{c}\text { Linear } \\
\text { heptapeptide }\end{array}$ \\
\hline Rhizopus stolonifer & 62.5 & 62.5 & 62.5 \\
Fusarium oxysporum & 62.5 & 62.5 & 62.5 \\
Aspergillus ochraceus & 62.5 & 62.5 & 31.25 \\
Penicillium notatum & 31.25 & 62.5 & 31.25 \\
Aspergillus flavus & 62.5 & 125 & 125 \\
Escherichia coli & 250 & 500 & 250 \\
Staphylococcus aureus & 250 & 500 & 500 \\
\hline
\end{tabular}

COM domains impairs rather than halts product formation. In contrast, formation of plipastatin was not only impaired but completely abrogated when donor modules of COM domains were changed, and resulted in formation of new assembly lines (ppsA/ppsB/ppsC/ppsD and ppsA/ppsB/ppsC/ppsE) that synthesized novel lipononapeptide and lipoheptapeptide products. These results further demonstrated that donor COM domains influence interactions in the biosynthetic assembly line. Deletion of the ppsC donor ceased the interaction with its partner acceptor module, but when the partner acceptor module was mutated to the acceptor of $\mathrm{ppsB}$, which facilitated the synthesis of a novel assembly line (ppsA/ppsB/ppsD/ppsE). Therefore, the acceptor COM domains retain selectivity when their partner donor is deleted. It was previously shown that when all donor and acceptor were replaced with the same (compatible) $\mathrm{COM}^{\mathrm{D}}$ and $\mathrm{COM}^{\mathrm{A}}$ domains in the surfactin biosynthetic complex, different assembly lines (SrfA-A/SrfA-B/SrfA-C and SrfA-A/SrfA-C) were formed that led to the synthesis of lipoheptapeptide and the lipotetrapeptide products (Chiocchini et al., 2006). A universal communication system for the plipastatin biosynthetic complex is therefore likely to result in additional novel lipopeptides.

Nonribosomal peptides synthetases (NRPSs) synthesis structurally diverse peptide-based natural products (Marahiel and Essen, 2009). Manipulation of their modular organization provides enormous potential for generating novel bioactive compounds (Miao et al., 2006; Butz et al., 2008; Doekel et al., 2008). Matching pairs of COM domains form proteinprotein interactions (Linne et al., 2003; Hahn and Stachelhaus,

\section{REFERENCES}

Anagnostopoulos, C., and Spizizen, J. (1961). Requirements for transformation in Bacillus subtilis. J. Bacteriol. 81, 741.

Arnaud, M., Chastanet, A., and Débarbouillé, M. (2004). New vector for efficient allelic replacement in naturally nontransformable, low-GC-content, gram-positive bacteria. Appl. Environ. Microbiol. 70, 6887-6891. doi: 10.1128/AEM.70.11.6887-6891.2004

Batool, M., Khalid, M. H., Hassan, M. N., and Hafeez, F. Y. (2011). Homology modeling of an antifungal metabolite plipastatin synthase from the bacillus subtilis 168. Bioinformation 7, 384-387. doi: 10.6026/97320630007384

Bonmatin, J.-M., Laprévote, O., and Peypoux, F. (2003). Diversity among microbial cyclic lipopeptides: iturins and surfactins. Activity-structure relationships to
2006), and the present study demonstrated the decisive role of COM domain pairs in NRP biosynthetic complexes. The need for new antibiotics to fight the emergence of resistant pathogenic microorganisms is growing (Marr et al., 2006), and the novel lipopeptides proved to have good antimicrobial activity.

\section{CONCLUSIONS}

Our results and experimental approaches pave the way for (1) identifying key residues in COM domains (2) characterizing the interactions between donor and acceptor COM domains, and (3) the preparation of novel lipopeptides possessing antimicrobial activity. Donor or acceptor modules could therefore influence the selectivity of NRPS systems. We demonstrated that (1) a single point mutation of a COM domain can alter the selectivity of the biosynthetic assembly line, (2) donor COM domains influence interactions in the biosynthetic assembly line, (3) mutation of acceptor COM domains impairs rather than halts product formation, (4) acceptor COM domains retain selectivity when their partner donor is deleted, and (5) the lipopeptides possess strong antifungal and some antibacterial activity. Our experimental approaches provide the theoretical basis for the production of the novel lipopeptides, which has potential for use in food preservation.

\section{AUTHOR CONTRIBUTIONS}

$\mathrm{XB}$ conceived the project and revising it critically for important intellectual content, HL and LG designed the experiments, HL analyzed the data and wrote the manuscript. $\mathrm{CD}, \mathrm{JH}$, and $\mathrm{ZM}$ assisted in data analysis, $\mathrm{XB}, \mathrm{ZL}$, and $\mathrm{CZ}$ supervised the study.

\section{ACKNOWLEDGMENTS}

This work was supported by grants from the National Natural Science Foundation of China (grant no. 31271828).

\section{SUPPLEMENTARY MATERIAL}

The Supplementary Material for this article can be found online at: http://journal.frontiersin.org/article/10.3389/fmicb. 2016.01801/full\#supplementary-material

design new bioactive agents. Comb. Chem. High Throughput Screen. 6, 541-556. doi: $10.2174 / 138620703106298716$

Butz, D., Schmiederer, T., Hadatsch, B., Wohlleben, W., Weber, T., and Süssmuth, R. D. (2008). Module extension of a non-ribosomal peptide synthetase of the glycopeptide antibiotic balhimycin produced by amycolatopsis balhimycina. Chembiochem 9, 1195-1200. doi: 10.1002/cbic.2008 00068

Calcott, M. J., and Ackerley, D. F. (2014). Genetic manipulation of non-ribosomal peptide synthetases to generate novel bioactive peptide products. Biotechnol. Lett. 36, 2407-2416. doi: 10.1007/s10529-014-1642-y

Cheng, Y. C., Ke, W. J., and Liu, S. T. (2016). Regions involved in fengycin synthetases enzyme complex formation. J. Microbiol. Immunol. Infect. doi: 10.1016/j.jmii.2015.12.001. [Epub ahead of print]. 
Chin, J. W., Martin, A. B., King, D. S., Wang, L., and Schultz, P. G. (2002). Addition of a photocrosslinking amino acid to the genetic code of Escherichia coli. Proc. Natl. Acad. Sci. U.S.A. 99, 11020-11024. doi: 10.1073/pnas.1722 26299

Chiocchini, C., Linne, U., and Stachelhaus, T. (2006). In vivo biocombinatorial synthesis of lipopeptides by COM domain-mediated reprogramming of the surfactin biosynthetic complex. Chem. Biol. 13, 899-908. doi: 10.1016/j.chembiol.2006.06.015

de Faria, A. F., Stéfani, D., Vaz, B. G., Silva, Í. S., Garcia, J. S., Eberlin, M. N., et al. (2011). Purification and structural characterization of fengycin homologues produced by Bacillus subtilis LSFM-05 grown on raw glycerol. J. Ind. Microbiol. Biotechnol. 38, 863-871. doi: 10.1007/s10295-011-0980-1

de Ferra, F., Rodriguez, F., Tortora, O., Tosi, C., and Grandi, G. (1997). Engineering of peptide synthetases key role of the thioesterase-like domain for efficient production of recombinant peptides. J. Biol. Chem. 272, 25304-25309. doi: $10.1074 / j b c .272 .40 .25304$

Dehling, E., Volkmann, G., Matern, J. C., Dörner, W., Alfermann, J., Diecker, J., et al. (2016). Mapping of the communication-mediating interface in nonribosomal peptide synthetases using a genetically encoded photocrosslinker supports an upside-down helix-hand motif. J. Mol. Biol. 428, 4345-4360. doi: 10.1016/j.jmb.2016.09.007

Deleu, M., Paquot, M., and Nylander, T. (2008). Effect of fengycin, a lipopeptide produced by Bacillus subtilis, on model biomembranes. Biophys. J. 94, 2667-2679. doi: 10.1529/biophysj.107.114090

Deng, Y., Lu, Z., Lu, F., Wang, Y., and Bie, X. (2011a). Study on an antimicrobial protein produced by Paenibacillus polymyxa JSa-9 isolated from soil. World J. Microbiol. Biotechnol. 27, 1803-1807. doi: 10.1007/s11274-010-0638-6

Deng, Y., Lu, Z., Lu, F., Zhang, C., Wang, Y., Zhao, H., et al. (2011b). Identification of LI-F type antibiotics and di-n-butyl phthalate produced by Paenibacillus polymyxa. J. Microbiol. Methods 85, 175-182. doi: 10.1016/j.mimet.2011.02.013

Doekel, S., Coëffet-Le Gal, M. F., Gu, J. Q., Chu, M., Baltz, R. H., and Brian, P. (2008). Non-ribosomal peptide synthetase module fusions to produce derivatives of daptomycin in Streptomyces roseosporus. Microbiology 154, 2872-2880. doi: 10.1099/mic.0.2008/020685-0

Eppelmann, K., Stachelhaus, T., and Marahiel, M. A. (2002). Exploitation of the selectivity-conferring code of nonribosomal peptide synthetases for the rational design of novel peptide antibiotics. Biochemistry 41, 9718-9726. doi: 10.1021/bi0259406

Finking, R., and Marahiel, M. A. (2004). Biosynthesis of nonribosomal peptides 1. Annu. Rev. Microbiol. 58, 453-488. doi: 10.1146/annurev.micro. 58.030603.123615

Fischbach, M. A., and Walsh, C. T. (2006). Assembly-line enzymology for polyketide and nonribosomal peptide antibiotics: logic, machinery, and mechanisms. Chem. Rev. 106, 3468-3496. doi: 10.1021/cr0503097

Guo, Q., Dong, W., Li, S., Lu, X., Wang, P., Zhang, X., et al. (2014). Fengycin produced by Bacillus subtilis NCD-2 plays a major role in biocontrol of cotton seedling damping-off disease. Microbiol. Res. 169, 533-540. doi: 10.1016/j.micres.2013.12.001

Hahn, M., and Stachelhaus, T. (2004). Selective interaction between nonribosomal peptide synthetases is facilitated by short communication-mediating domains. Proc. Natl. Acad. Sci. U.S.A. 101, 15585-15590. doi: 10.1073/pnas.0404932101

Hahn, M., and Stachelhaus, T. (2006). Harnessing the potential of communication-mediating domains for the biocombinatorial synthesis of nonribosomal peptides. Proc. Natl. Acad. Sci. U.S.A. 103, 275-280. doi: 10.1073/pnas.0508409103

Hiradate, S., Yoshida, S., Sugie, H., Yada, H., and Fujii, Y. (2002). Mulberry anthracnose antagonists (iturins) produced by Bacillus amyloliquefaciens RC-2. Phytochemistry 61, 693-698. doi: 10.1016/S0031-9422(02)00365-5

Honma, M., Tanaka, K., Konno, K., Tsuge, K., Okuno, T., and Hashimoto, M. (2012). Termination of the structural confusion between plipastatin A1 and fengycin IX. Bioorg. Med. Chem. 20, 3793-3798. doi: 10.1016/j.bmc.2012. 04.040

Jin, H., Zhang, X., Li, K., Niu, Y., Guo, M., Hu, C., et al. (2014). Direct bio-utilization of untreated rapeseed meal for effective iturin A production by Bacillus subtilis in submerged fermentation. PLOS ONE 9:e111171. doi: 10.1371/journal.pone.0111171

Landy, M., Rosenman, S. B, and Warren, G. H. (1947). An antibiotic from Bacillus subtilis active against pathogenic fungi. J. Bacteriol. 54, 24-24.
Linne, U., Stein, D. B., Mootz, H. D., and Marahiel, M. A. (2003). Systematic and quantitative analysis of protein-protein recognition between nonribosomal peptide synthetases investigated in the tyrocidine biosynthetic template. Biochemistry 42, 5114-5124. doi: 10.1021/bi034223o

Liu, Q., Lin, J., Wang, W., Huang, H., and Li, S. (2015). Production of surfactin isoforms by Bacillus subtilis BS-37 and its applicability to enhanced oil recovery under laboratory conditions. Biochem. Eng. J. 93, 31-37. doi: 10.1016/j.bej.2014.08.023

Marahiel, M. A., Stachelhaus, T., and Mootz, H. D. (1997). Modular peptide synthetases involved in nonribosomal peptide synthesis. Chem. Rev. 97, 2651-2674. doi: $10.1021 / \mathrm{cr} 960029 \mathrm{e}$

Marahiel, M. A., and Essen, L. O. (2009). Nonribosomal peptide synthetases: mechanistic and structural aspects of essential domains. Meth. Enzymol. 458, 337-351. doi: 10.1016/S0076-6879(09)04813-7

Marr, A. K., Gooderham, W. J., and Hancock, R. E. (2006). Antibacterial peptides for therapeutic use: obstacles and realistic outlook. Curr. Opin. Pharmacol. 6, 468-472. doi: 10.1016/j.coph.2006.04.006

Miao, V., Coëffet-Le Gal, M.-F., Nguyen, K., Brian, P., Penn, J., Whiting, A., et al. (2006). Genetic engineering in Streptomyces roseosporus to produce hybrid lipopeptide antibiotics. Cell Chem. Biol. 13, 269-276. doi: 10.1016/j.chembiol.2005.12.012

Mootz, H. D., Kessler, N., Linne, U., Eppelmann, K., Schwarzer, D., and Marahiel, M. A. (2002). Decreasing the ring size of a cyclic nonribosomal peptide antibiotic by in-frame module deletion in the biosynthetic genes. J. Am. Chem. Soc. 124, 10980-10981. doi: 10.1021/ja027276m

Mootz, H. D., Schwarzer, D., and Marahiel, M. A. (2000). Construction of hybrid peptide synthetases by module and domain fusions. Proc. Natl. Acad. Sci. U.S.A. 97, 5848-5853. doi: 10.1073/pnas.100075897

Nedorostova, L., Kloucek, P., Kokoska, L., Stolcova, M., and Pulkrabek, J. (2009). Antimicrobial properties of selected essential oils in vapour phase against foodborne bacteria. Food Control. 20, 157-160. doi: 10.1016/j.foodcont. 2008.03.007

Oh, I., Yang, W-Y, Park, J., Lee, S., Mar, W., Oh, K-B, et al. (2011). In vitro $\mathrm{Na}+/ \mathrm{K}+$-ATPase inhibitory activity and antimicrobial activity of sesquiterpenes isolated from Thujopsis dolabrata. Arch. Pharm. Res. 34, 2141-2147. doi: 10.1007/s12272-011-1218-5

Pathak, K. V., Bose, A., and Keharia, H. (2013). Characterization of novel lipopeptides produced by Bacillus tequilensis P15 Using Liquid Chromatography Coupled Electron Spray Ionization Tandem Mass Spectrometry (LC-ESI-MS/MS). Int. J. Pept. Res. Ther. 20, 133-143. doi: 10.1007/s10989-013-9375-7

Sambrook, J., Fritsch, E. F., and Maniatis, T. (1989). Molecular Cloning. New York, NY: Cold spring harbor laboratory press.

Schneider, A., Stachelhaus, T., and Marahiel, M. (1998). Targeted alteration of the substrate specificity of peptide synthetases by rational module swapping. Mol. Gen. Genet. 257, 308-318. doi: 10.1007/s004380050652

Schwarzer, D., Finking, R., and Marahiel, M. A. (2003). Nonribosomal peptides: from genes to products. Nat. Prod. Rep. 20, 275. doi: 10.1039/b111145k

Sieber, S. A., and Marahiel, M. A. (2005). Molecular mechanisms underlying nonribosomal peptide synthesis: approaches to new antibiotics. Chem. Rev. 105, 715-738. doi: 10.1021/cr0301191

Sun, L., Lu, Z., Bie, X., Lu, F., and Yang, S. (2006). Isolation and characterization of a co-producer of fengycins and surfactins, endophytic Bacillus amyloliquefaciens ES-2, from Scutellaria baicalensis Georgi. World J. Microbiol. Biotechnol. 22, 1259-1266. doi: 10.1007/s11274-006-9170-0

Tosato, V., Albertini, A. M., Zotti, M., Sonda, S., and Bruschi, C. V. (1997). Sequence completion, identification and definition of the fengycin operon in Bacillus subtilis 168. Microbiology 143, 3443-3450. doi: 10.1099/00221287-14311-3443

Vanittanakom, N., Loeffler, W., Koch, U., and Jung, G. (1986). FengycinA novel antifungal lipopeptide antibiotic produced by Bacillus subtilis F-29-3. J. Antibiot. 39, 888-901. doi: 10.7164/antibiotics. 39.888

Vater, J., Kablitz, B., Wilde, C., Franke, P., Mehta, N., and Cameotra, S. S. (2002). Matrix-assisted laser desorption ionization-time of flight mass spectrometry of lipopeptide biosurfactants in whole cells and culture filtrates of Bacillus subtilis C-1 isolated from petroleum sludge. Appl. Environ. Microbiol. 68, 6210-6219. doi: 10.1128/AEM.68.12.6210-6219.2002 
Walsh, C. T. (2002). Combinatorial biosynthesis of antibiotics: challenges and opportunities. Chembiochem 3, 124-134. doi: 10.1002/1439-7633 (20020301)3:2/3<124::AID-CBIC124>3.0.CO;2-J

Yang, H., Li, X., Li, X., Yu, H., and Shen, Z. (2015). Identification of lipopeptide isoforms by MALDI-TOF-MS/MS based on the simultaneous purification of iturin, fengycin, and surfactin by RP-HPLC. Anal. Bioanal. Chem. 407, 2529-2542. doi: 10.1007/s00216-015-8486-8

Yu, G., Sinclair, J., Hartman, G., and Bertagnolli, B. (2002). Production of iturin A by Bacillus amyloliquefaciens suppressing Rhizoctonia solani. Soil Biol. Biochem. 34, 955-963. doi: 10.1016/S0038-0717(02)00027-5
Conflict of Interest Statement: The authors declare that the research was conducted in the absence of any commercial or financial relationships that could be construed as a potential conflict of interest.

Copyright $\odot 2016$ Liu, Gao, Han, Ma, Lu, Dai, Zhang and Bie. This is an open-access article distributed under the terms of the Creative Commons Attribution License (CC $B Y)$. The use, distribution or reproduction in other forums is permitted, provided the original author(s) or licensor are credited and that the original publication in this journal is cited, in accordance with accepted academic practice. No use, distribution or reproduction is permitted which does not comply with these terms. 